\title{
Analysis of the Risk-Factors of Cardio-Vascular Disease in Russia and Its Regions
}

\author{
Farida Ishkineeva ${ }^{1}$, Simbul Akhmetova $^{1}$, Raushania Gaifullina $^{1} \&$ Farid Ishkineev $^{2}$ \\ ${ }^{1}$ Kazan Federal University, Kazan, Russia \\ ${ }^{2}$ Medical unit of Russian Federation Ministry of the Interior in the Republic of Tatarstan, Kazan, Russia \\ Correspondance: Farida Ishkineeva, Institute of Socio-Philosophic Sciences and Mass Communications, 420008, \\ Kazan, Republic of Tatarstan, Russian Federation. Tel: 7-843-233-78 41. E-mail: farida1967@mail.ru
}

Received: September 10, 2014

Accepted: September 29, $2014 \quad$ Online Published: December 10, 2014

doi:10.5539/mas.v9n1p157

URL: http://dx.doi.org/10.5539/mas.v9n1p157

\begin{abstract}
For the long time in the structure of the mortality reasons the dominant role belongs to the circulatory diseases, which are determine more than half of the deaths. At the same time, the situation differs in different countries and there are evidences that in most of the developed countries the rate of the deaths caused by cardio-vascular diseases is significantly lower than in Russia. It's necessary to organize further researches dedicated to the determination of the risk factors in Russia and its regions to determine the causes of deaths.
\end{abstract}

Keywords: cardio-vascular diseases, mortality, risk factors, population, smoking, alcoholization, healthy life style, multidisciplinary approach

\section{Introduction}

Cardio-vascular diseases are continuously taking the leading positions among the mortality reasons of the most countries. Death rates from specific types of cardiovascular diseases in Russia significantly differ from the death rates in developed European countries. Death rate in Russia is the same as in some African countries, so according to the statistics crude mortality rate in 2013 was 14,2 to 1000 people, while natural population loss was 1,2 to 1000 people. Dynamics of crude mortality rate from 2000 to 2013 indicates slow decrease, so in 2000 it was 15,3 to 1000 people, and the variation rate during this period was 1,9 per mille (World Health Orgamization, 2013). However, natural population loss continues today, we still have high death rate, including active working aged people. Cardio-vascular disease is the first one in the structure of the death reasons; cardio-vascular disease become the reason of death of 1,3 millions of Russians every year, which is $56 \%$ of all of the registered deaths (Demographical situation in Volga Federal district from January to December, 2013).

\section{Materials and Methods}

The basis for the research is statistical data concerning illnesses and mortality of the Russian population and the population of the Republic of Tatarstan, received from the population census of 2010 and current statistics, World Health Organization data, and the results of medico-sociological researches held in different regions of Russia and world. The following methods were used during the research: comparative analysis of statistics concerning cardio-vascular disease and mortality of different countries, secondary analysis of the results of previous researches of the topic of Russian and foreign researches.

According to the WHO, Russia is in the list of the highest number of deaths from cardio-vascular diseases. Russian rates for men and women are the highest among 33 countries (World Health Organization, 2013). 
Table 1.

\section{Circulation January 1/8, 2013}

\begin{tabular}{|c|c|c|c|c|}
\hline & CVO Deatss & CAD Denths & Strike Deatls & Total Deafis \\
\hline \multicolumn{5}{|l|}{ Men apes 35-74 y } \\
\hline Russien Federaten (2000) & 1185.4 & 658.5 & 307.5 & 2438.3 \\
\hline Bulgarie (2006) & 803.7 & 219.4 & 2182 & 1554.3 \\
\hline Ltharia (2000) & 784.7 & 44.6 & 138.3 & 1842.3 \\
\hline Ronaria (2016) & 657.9 & 260.2 & 195.9 & 1543.4 \\
\hline Hungry (2009) & 606.6 & 319.1 & 121.1 & 16623 \\
\hline \multirow{2}{*}{\multicolumn{5}{|c|}{ Russian rates for men and women are the highest }} \\
\hline & & & & \\
\hline Finland 0000 & 284.4 & 170.0 & 4388 & $\$ 392$ \\
\hline Unind Strins (2009) & 200.3 & 143.1 & 20.5 & 347.5 \\
\hline \multicolumn{5}{|l|}{ Women apes 35-74 y } \\
\hline Asssian Federaten [2009) & 453.0 & 2212 & 157.5 & 918.5 \\
\hline Bdgaria (2008) & 368.6 & 70.9 & 120.6 & 600.3 \\
\hline Romania (2010) & 312.2 & 105.7 & 111.4 & $6 e 2.4$ \\
\hline Ltharia (2009) & 2589 & 127.5 & $r . s$ & 646 \\
\hline Kuwaít (2009) & 246.1 & 94.8 & 56.1 & seat. \\
\hline Hangry (2009) & 2392.2 & 113.7 & 56.0 & 79.4 \\
\hline Slovizia 12000 & 220.5 & 129.7 & 57.5 & 5907 \\
\hline
\end{tabular}

Tendencies in the Republic of Tatarstan are generally the same as in Russia, the crude mortality rate is slightly lower than in Russia 13,3 per mille in 2000 (Comitee of the statistics of the Republic of Tatarstan. Public Health Service in the Republic of Tatarstan, 2013) and 12,1 per mille in 2013 (Demographical situation in Volga Federal district from January to December, 2013).

At the same time there are gender differences of the death rate generally in Russia and in Tatarstan, so the male death rate was higher approximately on 3 per mille than female death rate during the studied period (Comitee of the statistics of the Republic of Tatarstan. Women and men from Tatarstan, 2013)

According to the statistics from population census of 2010 in the Republic of Tatarstan and current data circulatory disease has leading positions in the list of the death reasons; and it's a stable tendency, high mortality from circulatory diseases becomes the main reasons of death for many years. Besides that, there is rejuvenation of circulation and cardio-vascular diseases, although they were previously concerned as elderly people diseases.

Annually from $54 \%$ to $65 \%$ of Tatarstan citizens die from circulatory diseases, and there has been a tendency to its decrease only in 2010. The duration of this tendency indicates the stability of reasons determining behavioral practices of the republic residents.

There is a number of reasons influencing chronic ailments, such as globalization, urbanization, ageing of population, poverty and stress. At the same time, analysis of common risk factors of cardio-vascular diseases doesn't provide an explanation of significant differences between Russia and other countries.

Apparently, the reasons of high mortality rate in Russia have societal character, and it is determined by unfavorable socio-economical situation in country in 1990s caused by structural crisis in every sector of the society. What has lead to deep stratification of society according to economical and social factors, marginalization significant part of population and active downward social mobility.

Unfavorable social conditions became significant destabilizing factor which has lead to decrease of the life quality and, consequently, break of the rules of healthy lifestyle (the lack of physical activity, smoking, and alcohol consumption, drugs).

The number of smokers in Russia annually increase on 1,5-2\%, including women and youth. The rate of growth of the number of smokers is the highest in Russia (Hazardous smoking, 2014).

The prominent factor of the mortality from cardio-vascular diseases is drug diseases, including hazardous alcohol consumption, alcohol psychosis, alcohol cardiomyopathy and so on. 
Table 2. Dynamics of mortality caused by alcohol consumption, Tatarstan, to 100000 people (Comitee of the statistics of the Republic of Tatarstan. Population size, composition, and demographic development in the Republic of Tatarstan, 2013).

\begin{tabular}{lllllll}
\hline Year & 2007 & 2008 & 2009 & 2010 & 2011 & 2012 \\
\hline Total number of dead & 22,5 & 22,0 & 19,1 & 22,2 & 23,0 & 23,3 \\
$\begin{array}{l}\text { Number of dead in active } \\
\text { working age }\end{array}$ & 28,4 & 27,4 & 23,0 & 26,4 & 27,3 & 30,0 \\
\hline
\end{tabular}

At the same time there is strong gender differentiation of death rates, so male deaths are higher than female rates 3 times in total, and 4 times in active working age (Comitee of the statistics of the Republic of Tatarstan. Public Health Service in the Republic of Tatarstan, 2013).

Medico-sociological research of London School of Hygiene and Tropical Medicine, held in Izhevsk in two stages in 2003-2008 and 2008-2010 using qualitative and quantitative measures has displayed strong connection between alcoholization and cardio-vascular diseases. Whilst male of the active working age were also included in the risk group.

Table 3. Variation of the correlation between alcohol consumption and mortality, according to the circulatory disease Man at the age of 25-54, Izhevsk, 2003-2005 (Leon, 2010)

\begin{tabular}{lll}
\hline Death reason & $\begin{array}{l}\text { Number } \\
\text { of deaths }\end{array}$ & $\begin{array}{l}\text { Hazardous alcohol consumption } \\
\text { OR* }(95 \% \mathrm{CI})\end{array}$ \\
\hline Alcohol cardiomyopathy & 98 & $15,70(9.5,25.94)$ \\
Other cardiomyopathy & 51 & $3.84(2.05,7.18)$ \\
Cerebrovascular disease & 90 & $2.05(1.24,3.40)$ \\
Other circulatory diseases & 28 & $3.43(1.58,7.81)$ \\
Ischemic heart disease & 219 & $3.04(2.17,4.24)$ \\
\hline
\end{tabular}

OR* adjusted for age, smoking and education.

Analysis of the data in table demonstrates strong correlation of cardiomyopathy at the men of working age from hazardous alcohol consumption. That's why one of the main hypotheses of international research of risk-factors of cardio-vascular diseases at Kazan population initiated by London School of Hygiene and Topical Medicine and Kazan Federal University was the hypothesis that hazardous alcohol consumption is the main reason of circulatory disease (Leon, 2010).

\section{Conclusions}

For deeper diagnosis of illnesses and mortality reasons in the Republic of Tatarstan, and first of all, Kazan, it is necessary to organize further researches dedicated to indication of the risk factors in Russia and its regions, and analysis of existing standards, preventive measures, diagnosis and treatment of cardio-vascular diseases. Multidisciplinary projects, where medical (laboratory-clinical researches) and sociological (life style peculiarities, and health value) approaches are taken in consideration at the same time, can be truly effective. Such researches are productive from the position of causes and prevent measures of diseases, since only multidisciplinary approach can help determining the reasons and risk factors of different diseases, and apart from that, heath culture, the information about person's conditions and social well-being of population.

\section{Acknowledgments}

The work was funded by the subsidy allocated to Kazan Federal University for the state assignment in the sphere of scientific activities.

\section{References}

Cardio-vascular diseases. (2013). World Health Organization. Retrieved June 26, 2014, from www.who.int/mediacentre/factsheets/fs317/en/

Comitee of the statistics of the Republic of Tatarstan. (2013). Population size, composition, and demographic development in the Republic of Tatarstan. Statistics digest: Kazan

Comitee of the statistics of the Republic of Tatarstan. (2013). Public Health Service in the Republic of Tatarstan. 
Statistics digest: Kazan

Comitee of the statistics of the Republic of Tatarstan. (2013). Women and men from Tatarstan. Statistics digest: Kazan

Demographical situation in Volga Federal district from June to December. (2013). Social sphere. Retrieved June 26, 2014, from http://www.pfo.ru>id74403

Federal Service for National Statistics. (2013). Russian demography. Retrieved June 26, 2014, from

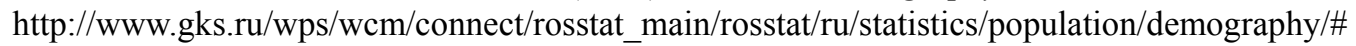

Hazardous smoking. (2014). Retrieved February 25, 2014, from http:// www.protivkureniya.ru/

Leon, D. A., Shkolnikov, V. M., McKee, M., Kiryanov, N., \& Andreev, E. (2010). Alcohol increases circulatory disease mortality in Russia: Acute and chronic effects or misattribution of cause? International Journal of Epidemiology, 39(5), 1279-1290. http://dx.doi.org/10.1093/ije/dyq102

Leon, D. A., Shkolnikov, V. M., McKee, M., Kiryanov, N., \& Andreev, E. (2010). Alcohol increases circulatory disease mortality in Russia: Acute and chronic effects or misattribution of cause? International Journal of Epidemiology, 39(5), 1279-1290. http://dx.doi.org/10.1093/ije/dyq102

\section{Copyrights}

Copyright for this article is retained by the author(s), with first publication rights granted to the journal.

This is an open-access article distributed under the terms and conditions of the Creative Commons Attribution license (http://creativecommons.org/licenses/by/3.0/). 